\title{
Sulphate, more than a nutrient, protects the microalga Chlamydomonas moewusii from cadmium toxicity
}

\author{
Roi Mera, Enrique Torres", Julio Abalde \\ Laboratorio de Microbiología, Facultade de Ciencias, Universidade da Coruña, 15071 A \\ Coruña, Spain
}

Aquatic Toxicology, Volume 148, March 2014, Pages 92-103

Received 17 October 2013, Revised 23 December 2013, Accepted 31 December 2013, Available online 10 January 2014

\section{How to cite:}

Mera, R., Torres, E., Abalde, J., 2014. Sulphate, more than a nutrient, protects the microalga chlamydomonas moewusii from cadmium toxicity. Aquat. Toxicol. 148, 92-103. doi:10.1016/j.aquatox.2013.12.034

\section{HIGHLIGHTS}

- Sulphate effect on cadmium toxicity in the microalga Chlamydomonas moewusii Gerloff.

- Cadmium increases the sulphur requirements in Chlamydomonas moewusii.

- Kinetic coefficients for sulphate utilization and cadmium effect on them.

- Sulphate and cadmium influence on the biosynthesis of low-molecular mass thiols.

- Cadmium toxicity reduction by sulphate due to higher biosynthesis of thiols.

\section{ABSTRACT}

Sulphur is an essential macroelement that plays important roles in living organisms. The thiol rich sulphur compounds, such as cysteine, $\gamma$-Glu-Cys, glutathione and phytochelatins participate in the tolerance mechanisms against cadmium toxicity. Plants, algae, yeasts and most prokaryotes cover their demand for reduced sulphur by 
reduction of inorganic sulphate. The aim of this study was to investigate, using a bifactorial experimental design, the effect of different sulphate concentrations in the nutrient solution on cadmium toxicity in the freshwater microalga Chlamydomonas moewusii. Cell growth, kinetic parameters of sulphate utilization and intracellular concentrations of low-molecular mass thiol compounds were determined. A mathematical model to describe the growth of this microalga based on the effects of sulphate and cadmium was obtained. An ANOVA revealed an interaction between them, $16 \%$ of the effect sizes was explained by this interaction. A higher amount of sulphate in the culture medium allowed a higher cadmium tolerance due to an increase in the thiol compound biosynthesis. The amount of low-molecular mass thiol compounds, mainly phytochelatins, synthesized by this microalga was significantly dependent on the sulphate and cadmium concentrations; the higher phytochelatin content was obtained in cultures with $4 \mathrm{mg} \mathrm{Cd} / \mathrm{L}$ and $1 \mathrm{mM}$ sulphate. The maximum $\mathrm{EC}_{50}$ value (based on nominal cadmium concentration) reached for this microalga was $4.46 \pm 0.42 \mathrm{mg} \mathrm{Cd} / \mathrm{L}$ when the sulphate concentration added to the culture medium was also $1 \mathrm{mM}$. An increase in the sulphate concentration, in deficient environments, could alleviate the toxic effect of this metal; however, a relative excess is also negative. The results obtained showed a substrate inhibition for this nutrient. An uncompetitive model for sulphate was chosen to establish the mathematical model that links both factors.

\section{KEYWORDS}

Sulphate; Cadmium; Low-molecular mass thiol compounds; Tolerance; Chlamydomonas moewusii; Toxicity

\section{INTRODUCTION}

The use of metals has increased exponentially from the Industrial Revolution. As result, metals can reach high concentrations, especially near the discharge site. The large increase in the circulation of these elements through the environment and their inevitable transfer to the human food chain remains an important environmental issue, which entails some unknown health risks for future generations. For a long time, 
cadmium has been classified as one of the most dangerous metals for organisms (Mislin and Ravera, 1986). After mercury and lead, it is the next most important metal as environmental pollutant. In particular, cadmium is one of the most hazardous metals for ecosystems, contributing to their deterioration. This metal represents a serious health hazard to man and animals (Järup, 2003 and WHO, 1992). The basis of cadmium toxicity lies on the competition with essential metals (Brzóska and MoniuszkoJakoniuk, 2001, Noël et al., 2006, Pawlik-Skowrońska, 2001, Prévot and SoyerGobillard, 1986 and Sunda and Huntsman, 1996) and its very strong affinity to biological structures containing-SH groups (mainly enzymes) (Jacobson and Turner, 1980 and Stohs and Bagchi, 1995). This toxicity affects all organisms, but especially those in direct contact with the metal, such as microalgae. For this reason, they need to develop diverse tolerance mechanisms in order to prevent or neutralize its potential toxic effect.

In microalgae, one of these intracellular mechanisms involves organic complexation of trace metals to maintain their concentrations at non-toxic levels. The two best-characterized metal-binding ligands in plants, fungi and algae are phytochelatins (PCs) and metallothioneins (MTs) (Cobbett and Goldsbrough, 2002). MTs are cysteine-rich polypeptides encoded by genes; however, PCs are enzymatically synthesized cysteine-rich peptides of low molecular weight (Rauser, 1990). The most common structure of PCs is formed by only three amino acids: glutamic acid (Glu), cysteine (Cys) and glycine (Gly), with the Glu and Cys residues linked through a $\gamma$ carboxylamide bond. PCs form a family of compounds with increasing repetitions of the $\gamma$-Glu-Cys dipeptide followed by a terminal Gly, resulting a structure: $(\gamma-\mathrm{Glu}-\mathrm{Cys}) n-$ Gly, where $n$ is generally in the range of $2-11$, depending on the organism ( Steffens, 1990, Torres et al., 1997 and Zenk, 1996). Different isoforms are currently known (Bräutigam et al., 2011). PCs are structurally related to the tripeptide glutathione (GSH; $\gamma$-Glu-Cys-Gly) which is the substrate for the biosynthesis of these peptides (Cobbett and Goldsbrough, 2002). This biosynthesis is catalyzed by the enzyme phytochelatin synthase (PCS), which is a $\gamma$-glutamylcysteine dipeptidyl transpeptidase (E.C.2.3.2.15) (Vatamaniuk et al., 2004). This enzyme is activated by certain metal ions, $\mathrm{Cd}^{2+}, \mathrm{Ag}^{+}$, $\mathrm{Cu}^{2+}, \mathrm{Au}^{+}, \mathrm{Zn}^{2+}, \mathrm{Fe}^{2+}, \mathrm{Hg}^{2+}$ and $\mathrm{Pb}^{2+}$ (Chen et al., 1997). However, $\mathrm{Cd}^{2+}$ is the most potent activator (Grill et al., 1987). The role of PCs in the metal tolerance is known since long ago. The main property of these peptides is their metal-binding capacity 
through the thiol group of the cysteine residues (Mason and Jenkins, 1995). These thiol groups allow PCs to bind with high affinity to metal ions and thereby to form a strong PC-metal complex. This property of forming strong metal complexes, for example with cadmium ions, is also due to the ability to incorporate high levels of inorganic sulphide (Mehra et al., 1994). This incorporation into PC-Cd complex results in $\mathrm{S}_{2} \mathrm{Cd}$ crystal formation, which can store cadmium more effectively, the thiol peptides acting as a coating of these crystals (Dameron and Winge, 1990). Finally, the PC-metal complex could end up in the cell vacuolar system ( Heuillet et al., 1986 and Ortiz et al., 1995).

Knowing and understanding these tolerance mechanisms may not be sufficient in an environmental framework. Thus, the knowledge of the environmental factors that can influence them may be important from an environmental point of view for improving a polluted environment and contribute to its bioremediation. Sulphur is an essential macroelement that plays an important role in the physiological processes of living organisms. It is found in many molecules, from amino acids to vitamins. Plants, algae, yeasts and most prokaryotes cover their demand for reduced sulphur by reduction of inorganic sulphate, which is then incorporated into organic compounds in its reduced form. This sulphate assimilation pathway involves the final biosynthesis of cysteine and methionine (Hell et al., 2008 and Wirtz and Droux, 2005). Cysteine is of particular interest in relation to metals because, as mentioned, this sulphur-containing amino acid is required for the GSH and PC biosynthesis, thus being an important pathway in the cadmium tolerance. Because of this, it would be interesting to study what would be the effect of a different bioavailability of sulphur in the environment on the tolerance to cadmium. In fact, in plants, a higher sulphur availability in soil allowed the GSH content to increase and this helped in reducing cadmium toxicity (Anjum et al., 2008). In aquatic environments the sulphate content is variable, it is usually found in low (about $0.01-0.5 \mathrm{mM}$ ) concentrations in most freshwater systems, which is much lower than in seawater, $28 \mathrm{mM}$ (Holmer and Storkholm, 2001). Given this reasoning, high sulphate levels could lead to a higher cadmium tolerance due to an increase in the biosynthesis of low-molecular mass thiols. This palliative effect on cadmium toxicity has not been studied intensively in aquatic environments with microalgal cells and could have interest in bioremediation and implementation of clean-up technologies for cadmium polluted environments. 
The aim of the present study was to investigate, using a bifactorial experimental design, the effect of different sulphate concentrations in the culture medium on cadmium toxicity in the freshwater microalga Chlamydomonas moewusii. This experiment was conducted in order to identify possible interactive effects between cadmium and sulphate on cell growth and the biosynthesis of low-molecular mass thiol compounds in this microalga. The kinetic parameters for sulphate utilization as nutrient under cadmium toxicity and the effects of this metal on them were also obtained.

\section{MATERIAL AND METHODS}

\subsection{Microorganism and culture conditions}

The microalgal species chosen for this study was Chlamydomonas moewusii Gerloff (strain CCAP 11/5B). This strain was obtained from the Culture Collection of Algae and Protozoa, Freshwater Ecology Institute (Cumbria, UK). Cells of this freshwater microalga were grown and maintained in modified Bristol medium (Brown et al., 1967) sterilized at $121{ }^{\circ} \mathrm{C}$ for $20 \mathrm{~min}$. The composition of the culture medium is shown in Table 1 . Different amounts of $\mathrm{Na}_{2} \mathrm{SO}_{4}$ were added depending on the experiments. Cultures were maintained at $18 \pm 1{ }^{\circ} \mathrm{C}$ under a light intensity of $68 \mu \mathrm{E} /\left(\mathrm{m}^{2} \mathrm{~s}\right)$ using cool fluorescent light with a light/dark cycle of 12:12 h. Natural sterile air was constantly bubbled at a flow rate of $10 \mathrm{~L} / \mathrm{min}$.

\subsection{Chemicals}

All chemicals used for the culture medium (Table 1) were of the highest purity available, cadmium chloride 21/2-hydrate $\left(\mathrm{CdCl}_{2} \cdot 2 \frac{1}{2} \quad \mathrm{H}_{2} \mathrm{O}\right)$, orthophosphoric acid $\left(\mathrm{H}_{3} \mathrm{PO}_{4}\right)$, boric acid $\left(\mathrm{H}_{3} \mathrm{BO}_{3}\right)$, hydrochloric acid $(\mathrm{HCl})$, sodium hydroxide $(\mathrm{NaOH})$, monobromobimane $\left(\mathrm{C}_{10} \mathrm{H}_{11} \mathrm{~N}_{2} \mathrm{O}_{2} \mathrm{Br}\right)$, sodium borohydride $\left(\mathrm{NaBH}_{4}\right)$, diethylenetriaminetetraacetic acid anhydride (DTPA, $\mathrm{C}_{14} \mathrm{H}_{19} \mathrm{~N}_{3} \mathrm{O}_{8}$ ), Lugol's ( $\mathrm{I}_{2}-\mathrm{KI}$ ), standards of Cys, $\gamma$-Glu-Cys and GSH were purchased from Sigma-Aldrich ${ }^{\circledR}$ (St. Louis, MO, USA). Standards of phytochelatins were purchased from AnaSpec, Inc. (Fremont, USA). Filters were obtained from Millipore (Millipore Ibérica, Spain). The different reagents, buffers and culture media were prepared with Milli- $Q^{\circledR}$ water obtained from a Milli $Q$ Plus system (Millipore Ibérica, Spain). 
Table 1. Composition of the culture medium for the experiments.

\begin{tabular}{ll}
\hline Compound & $(\mathrm{g} / \mathrm{L})$ \\
\hline $\mathrm{NaNO}_{3}$ & 0.250 \\
$\mathrm{KH}_{2} \mathrm{PO}_{4}$ & 0.175 \\
$\mathrm{~K}_{2} \mathrm{HPO}_{4}$ & 0.075 \\
$\mathrm{Na}_{2} \mathrm{SO}_{4}$ & Variable \\
$\mathrm{MgCl}_{2}$ & 0.029 \\
$\mathrm{CaCl}_{2} \cdot 2 \mathrm{H}_{2} \mathrm{O}$ & 0.029 \\
$\mathrm{NaCl}_{\mathrm{CoCl}} \cdot 6 \mathrm{H}_{2} \mathrm{O}$ & 0.025 \\
$\mathrm{MnCl}_{2} \cdot 4 \mathrm{H}_{2} \mathrm{O}$ & $4.0 \times 10^{-3}$ \\
$\mathrm{FeCl}_{3} \cdot 6 \mathrm{H}_{2} \mathrm{O}$ & $1.8 \times 10^{-3}$ \\
$\mathrm{MoO}_{4} \mathrm{Na}_{2} \cdot 2 \mathrm{H}_{2} \mathrm{O}$ & $5.1 \times 10^{-4}$ \\
$\mathrm{H}_{3} \mathrm{BO}_{3}$ & $3.9 \times 10^{-4}$ \\
$\mathrm{ZnCl}_{2}$ & $2.0 \times 10^{-4}$ \\
$\mathrm{CuCl}_{2}$ & $1.1 \times 10^{-4}$ \\
$\mathrm{pH}^{2} 6.8$ & $4.3 \times 10^{-5}$
\end{tabular}

\subsection{Cadmium and sulphate stock solutions}

A cadmium stock solution was prepared by dilution of cadmium chloride $2^{1 / 2}$ hydrate in Milli- $Q$ water to obtain a concentration of $10 \mathrm{~g} \mathrm{Cd}(\mathrm{II}) / \mathrm{L}$. This solution was filtered through a $0.22 \mu \mathrm{m}$ Millipore filter.

Sulphate stock solutions were prepared by dilution of anhydrous sodium sulphate in Milli- $Q$ water to obtain concentrations of $0.05,0.5,20$ and $250 \mathrm{mM}$. These solutions were filtered through a $0.22 \mu \mathrm{m}$ Millipore filter and sterilized at $121^{\circ} \mathrm{C}$ for $20 \mathrm{~min}$.

\subsection{Monobromobimane stock solution}

A monobromobimane $(\mathrm{mBrB})$ stock solution was prepared by dissolving $25 \mathrm{mg}$ $\mathrm{mBrB}$ in $1 \mathrm{~mL}$ dimethyl sulphoxide to obtain a concentration of $0.1 \mathrm{M}$. This solution was stored at $-20{ }^{\circ} \mathrm{C}$.

\subsection{Experimental design, cadmium and sulphate treatments}

C. moewusii was cultured in sterilized $500 \mathrm{~mL}$ Pyrex glass bottles for 4 days with the conditions listed above. In order to study the sulphate effect on cadmium tolerance 
in this microalga, a bifactorial experiment was used. The experimental design (cadmium levelvs. sulphate concentration) consisted of a specific cadmium concentration treated with various sulphate concentrations (one in each experiment). Thus, an appropriated volume of sodium sulphate stock solution was added to the culture medium to obtain the nominal $\mathrm{SO}_{4}{ }^{2-}$ concentrations of $0.0001,0.00025,0.0005,0.001,0.0025,0.005$, $0.01,0.025,0.05,0.1,0.25,0.5,1,2,3$ and $5 \mathrm{mM}$. An appropriate volume of cadmium stock solution was added to these cultures to obtain a nominal cadmium concentration of $1,2,4,6$ or $8 \mathrm{mg} / \mathrm{L}$. Finally, the inoculum, taken from a culture that was in a sulphate-free culture medium for 21 days to decrease the cellular pool of organic sulphur, was added. Initial cell density in the assays was $40 \times 10^{4}$ cells $/ \mathrm{mL}$. Control cultures without cadmium and sulphate were also included. There were 102 treatments, each treatment was carried out in triplicate (306 treatments in total).

\subsection{Growth measurement and kinetic studies}

Growth of the microalgal cultures was measured daily by counting aliquots in an improved Neubauer haemocytometer chamber (Marienfeld-Superior, Germany) after fixation with Lugol's solution and using a phase-contrast light microscope, Nikon Labophot (Nikon, Japan). This growth was expressed as cell density $\left(\times 10^{4}\right.$ cells $\left./ \mathrm{mL}\right) \pm$ standard error for all replicates of each treatment. The specific growth rate $(\mu)$ during the time of culture, expressed as $1 / d$, was also calculated from the following equation:

$$
\mu=\left[\frac{\operatorname{Ln}\left(N_{t}\right)-\operatorname{Ln}\left(N_{0}\right)}{\operatorname{Ln}(2)\left(t-t_{0}\right)}\right]
$$

where $N_{0}$ and $N t$ are the number of cells $/ \mathrm{mL}$ at initial and final time of the exponential growth period, and $t_{0}$ and $t$ are the corresponding times (days).

Three mathematical models (substrate inhibition models) for the $C$. moewusii growth with respect to sulphate (adapted from enzyme kinetics), competitive, uncompetitive and non-competitive (Eqs. (2), (3) and (4)), were tested to better predict the experimental data:

$$
\mu=\frac{\mu_{m} S}{K_{S}\left(1+S / K_{l}\right)+S}
$$




$$
\begin{aligned}
& \mu=\frac{\mu_{m} S}{K_{s}+S+S^{2} / K_{l}} \\
& \mu=\frac{\mu_{m} S}{\left(K_{S}+S\right)\left(1+S / K_{l}\right)}
\end{aligned}
$$

where $\mu$ is the specific growth rate, $\mu m$ is the specific growth constant $(1 / d), S$ is the sulphate concentration $(\mathrm{mM}), K s$ is the affinity constant or substrate saturation constant $(\mathrm{mM})$ and $K I$ is the inhibition constant, which numerically equals the highest substrate concentration $(\mathrm{mM})$ at which the specific growth rate is equal to one half the maximum specific growth. The equations were fitted to the obtained growth data by means of a nonlinear regression. The parameters $\mu m, K s$ and $K I$ were estimated from this regression.

Finally, the cadmium concentration corresponding to the median effective concentration $\left(\mathrm{EC}_{50}\right.$, metal concentration that reduces the population growth to $50 \%$ of the control) for this microalga was calculated using a log concentration-response curve for each sulphate treatment. The $\log [\mathrm{Cd}] v s$. the difference between the final cell densities (4 days of culture) obtained for each cadmium concentration and the control without cadmium were plotted and a nonlinear regression was performed. The $\mathrm{EC}_{50 / 4 \mathrm{~d}}$ was calculated from the regression equation obtained.

Curve fitting and analyses were performed using SigmaPlot 12.5 (Systat Software Inc., Chicago).

\subsection{Extraction and derivatization of biological samples for low-molecular} mass thiol compound determination

C. moewusii cells were harvested by centrifugation $(4000 \times g, 10 \mathrm{~min})$ after 4 days of growth and stored at $-80{ }^{\circ} \mathrm{C}$ until the analysis. Low-molecular mass thiol compounds were extracted from the frozen samples and derivatized with monobromobimane $(\mathrm{mBrB})$ that specifically labels sulfhydryl-containing compounds. The procedure was adapted from Pérez-Rama et al. (2005). Frozen samples were resuspended in an appropriated volume of $0.1 \mathrm{M} \mathrm{HCl}$. The cells were broken and homogenized with an ultrasonic cell disrupter in ice bath at $4{ }^{\circ} \mathrm{C}$ for $8 \mathrm{~min}$ (steps of $2 \mathrm{~min}$ ) and at $126 \mu \mathrm{m}$, using a Labsonic ${ }^{\circledR} \mathrm{P}$ ultrasonic homogenizer (Sartorius AG, Germany). Cell debris was removed by centrifugation $\left(13,000 \times g, 10 \mathrm{~min}, 4{ }^{\circ} \mathrm{C}\right)$. 
$500 \mu \mathrm{L}$ of this extract were added to $500 \mu \mathrm{L}$ of freshly prepared derivatization buffer. This buffer was made up of $1 \mathrm{M}$ sodium borate $(\mathrm{pH}=9), 1 \mathrm{mM}$ DTPA and $5 \mathrm{mg} / \mathrm{mL}$ $\mathrm{NaBH}_{4}$ as reducing agent. Once the solutions were mixed, the mixture was incubated at $4{ }^{\circ} \mathrm{C}$ in ice bath for $20 \mathrm{~min} .8 \mu \mathrm{L}$ of $0.1 \mathrm{M} \mathrm{mBrB}$ were added to the mixture and incubated at room temperature for $1 \mathrm{~h}$ in darkness. Afterwards, the mixture was centrifuged $\left(13,000 \times g, 10 \mathrm{~min}, 4^{\circ} \mathrm{C}\right)$. Finally, a supernatant volume of $500 \mu \mathrm{L}$ was transferred to a new vial and stored at $-80{ }^{\circ} \mathrm{C}$ until the injection into the electrophoretic system. Standards of cysteine, $\gamma$-Glu-Cys, GSH and phytochelatins were derivatized in the same way as the biological samples in order to identify and quantify the different peaks.

\subsection{Characterization and quantification of the low-molecular mass thiol} compounds derivatized with $\mathbf{m B r B}$

A capillary zone electrophoresis technique was used to separate, identify and quantify the diverse low-molecular mass thiol compounds (cysteine, GSH, $\gamma$-Glu-Cys and phytochelatins) in the derivatized biological samples. The equipment used was a $\mathrm{HP}^{3 \mathrm{D}} \mathrm{CE}$ (Capillary Electrophoresis System; Agilent Technologies, Waldbronn, Germany) equipped with a photodiode array detector.

The capillary electrophoresis conditions were adapted from Pérez-Rama et al. (2005). An uncoated fused silica capillary (Composite Metal Services Ltd., UK) with an internal diameter of $50 \mu \mathrm{m}, 375 \mu \mathrm{m}$ external diameter, $38 \mathrm{~cm}$ total length and $30 \mathrm{~cm}$ effective length was used. The temperature of the cassette containing the capillary was maintained at $25 \pm 1{ }^{\circ} \mathrm{C}$ with an air coolant control system. Prior to the runs, the capillary was rinsed with $1 \mathrm{M} \mathrm{NaOH}$ followed by deionized Milli- $Q$ water under a 50 mbar internal pressure, each for $3 \mathrm{~min}$. Then, the capillary was refilled with an electrolytic solution of $100 \mathrm{mM}$ sodium phosphate $(\mathrm{pH}=1.86)$ as running buffer. This electrolytic solution was filtered through a $0.22 \mu \mathrm{m}$ Millipore filter and degassed before use. The protocol for each run consisted in a $3 \mathrm{~min}$ pre-rinse with the electrolytic solution followed by the sample injection.

The derivatized samples were loaded into the anodic inlet end of the capillary by hydrodynamic injection at 50 mbar internal pressure applied for $9 \mathrm{~s}$. A voltage of $+17 \mathrm{kV}$ was used to perform the separation. Detection was set to a wavelength of 
$390 \mathrm{~nm}$. All separations were carried out at least in duplicate. System control, data collection, processing and analyses of electropherograms were performed using the Agilent ChemStation Software (Agilent Technologies).

\subsection{Statistical analysis}

Data were expressed as means \pm standard error. All data were analyzed using the statistical program SPSS 21.0 (SPSS Ibérica, Spain). A two-factor analysis of variance (ANOVA) was used to detect a possible interaction between cadmium and sulphate. Finally, data were compared with the post-hoc Tukey's multiple comparisons test, for a significance level of $5 \%(p<0.05)$.

\section{RESULTS}

\subsection{Effects of cadmium and sulphate on the $C$. moewusii growth}

These effects were studied during 4 days of culture using a bifactorial design. The statistical analysis of the data by ANOVA showed significant differences in the final cell density of the cultures for both factors $(F=33, p<0.05)$ (Table 2).

In cultures without cadmium, the sulphate concentrations assayed showed an enhanced the $C$. moewusii growth. This effect was directly proportional to the concentration of this macronutrient ( Fig. 1). The highest final cell density was obtained when the sulphate concentration initially added to the culture medium was $0.1 \mathrm{mM}$. Therefore, since sulphate is a macronutrient, the optimum concentration obtained in these experiments was $0.1 \mathrm{mM}$ for the initial cell density used. However, a decrease in the final cell density occurred from this concentration, which was also proportional to the sulphate concentration. This result indicated that there was substrate inhibition at sulphate concentrations higher than $0.1 \mathrm{mM}$. The ANOVA test and post-hoc analysis $(p<0.05)$ revealed that these effects were significant and therefore, sulphate exerted a beneficial effect on the growth of this microalga. This beneficial effect decreased from the concentration of $0.1 \mathrm{mM}$. 
Table 2. Results from ANOVA of the sulphate and cadmium effect on the final cell density of Chlamydomonas moewusii after 4 days of culture.

\begin{tabular}{lllllll}
\hline Factor & $\begin{array}{l}\text { Root } \\
\text { square } \\
(\text { RMS })\end{array}$ & mean & $\begin{array}{l}\text { Type-III sum } \\
\text { of squares }\end{array}$ & $F$ value & $p$ Value & $\begin{array}{l}\text { Effect } \\
(\%)\end{array}$
\end{tabular}

\begin{tabular}{llllll}
\hline \multicolumn{2}{l}{ Between subjects } & & & \\
Sulphate & $1.2 \mathrm{E}+13$ & $1.8 \mathrm{E}+14$ & 253 & 0.000 & 23 \\
Cadmium & $6.1 \mathrm{E}+13$ & $3.1 \mathrm{E}+14$ & 1308 & 0.000 & 38 \\
$\begin{array}{l}\text { Sulphate } \times \text { ca } \\
\text { dmium }\end{array}$ & $1.6 \mathrm{E}+12$ & $1.3 \mathrm{E}+14$ & 33 & 0.000 & 16 \\
Error & & & & & 7 \\
Total & $4.7 \mathrm{E}+10$ & $5.4 \mathrm{E}+13$ & & & \\
$\begin{array}{l}\text { Corrected } \\
\text { total }\end{array}$ & & $2.2 \mathrm{E}+15$ & & & \\
\end{tabular}

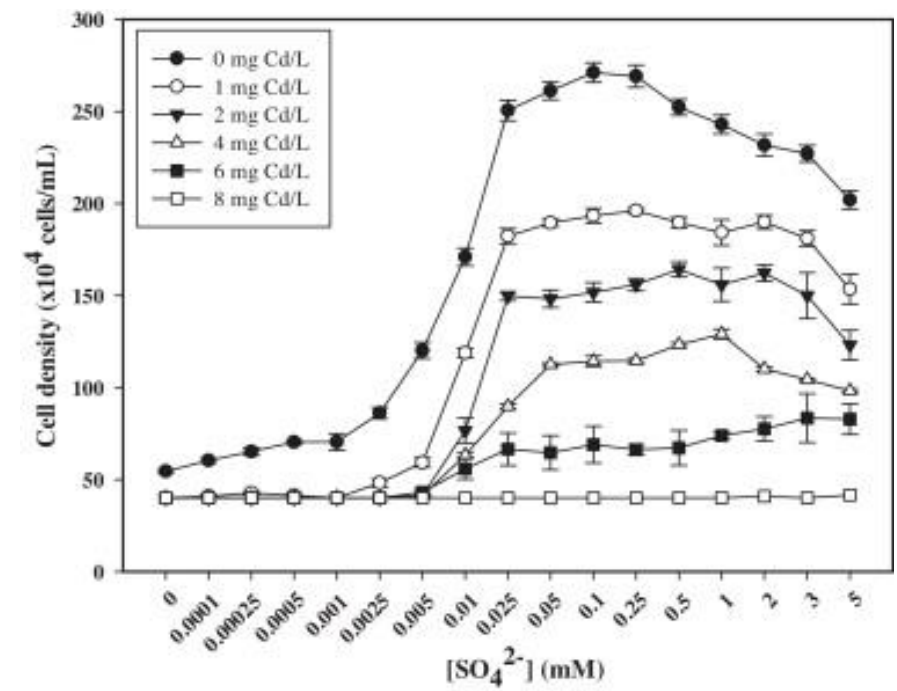

Fig. 1. Final cell densities of $C$. moewusii after 4 days of exposure to different cadmium and sulphate concentrations. Each point represents mean \pm standard error $(n=3)$. The $x$-axis is not to scale.

Regarding the cadmium effect, an inhibition on the $C$. moewusii growth was directly proportional to the metal concentration ( Fig. 1). This inhibitory effect increased progressively in the cultures treated with 1 to $6 \mathrm{mg} \mathrm{Cd} / \mathrm{L}$, presenting a reduction in the final cell density. Cultures treated with the highest cadmium concentration $(8 \mathrm{mg} / \mathrm{L})$ showed a total growth inhibition until the last day of culture. The ANOVA and Tukey's test $(p<0.05)$ revealed a significant cadmium effect on the $C$. moewusii growth after 4 days of exposure.

The ANOVA also revealed a statistically significant interaction between both factors, which is an important aspect to take into account in the process of tolerance to 
this metal. A $16 \%$ of effect sizes could be explained as effect of the sulphate-cadmium interaction (Table 2). Each individual factor had a significant effect on the cell growth of this microalga. Cadmium was identified as the most important factor of both, because $38 \%$ of effect sizes were due to this metal, while the sulphate effect was only $23 \%$. That is, the toxic effect of had a greater weight than the beneficial effect of sulphate as a nutrient on the growth of this microalga. The interaction between both factors can also be seen inFig. 1; when the sulphate concentration increased, the toxic effect of cadmium was lower. Cultures with low cadmium concentrations hardly grew or did not grow at all when the sulphate concentrations were very low. However, these cultures grew in the control cultures without cadmium. When the sulphate concentrations increased, the cultures with cadmium also increased their growth. In fact, $C$. moewusii cells treated with high sulphate concentrations $(0.1-5 \mathrm{mM})$ had growth, even at the highest cadmium concentrations (except $8 \mathrm{mg} / \mathrm{L}$ ), allowing growth at these concentrations. Therefore, $C$. moewusii required higher sulphate concentrations with the increase of cadmium concentration. As cadmium concentration increased, a higher sulphate concentration was required to achieve a final cell density close to the final cell density obtained in the cultures without cadmium. Thus, Fig. 2 was obtained when the amount of sulphate in which the maximum final cell density is reached, within each of the cadmium concentration, is plotted against this cadmium concentration. It can be observed from this figure that with the increase of cadmium in the culture medium, a higher amount of sulphate was required to achieve the corresponding maximum cell density. This maximum was reached with a smaller amount of sulphate $(0.1 \mathrm{mM})$ in cultures without cadmium.

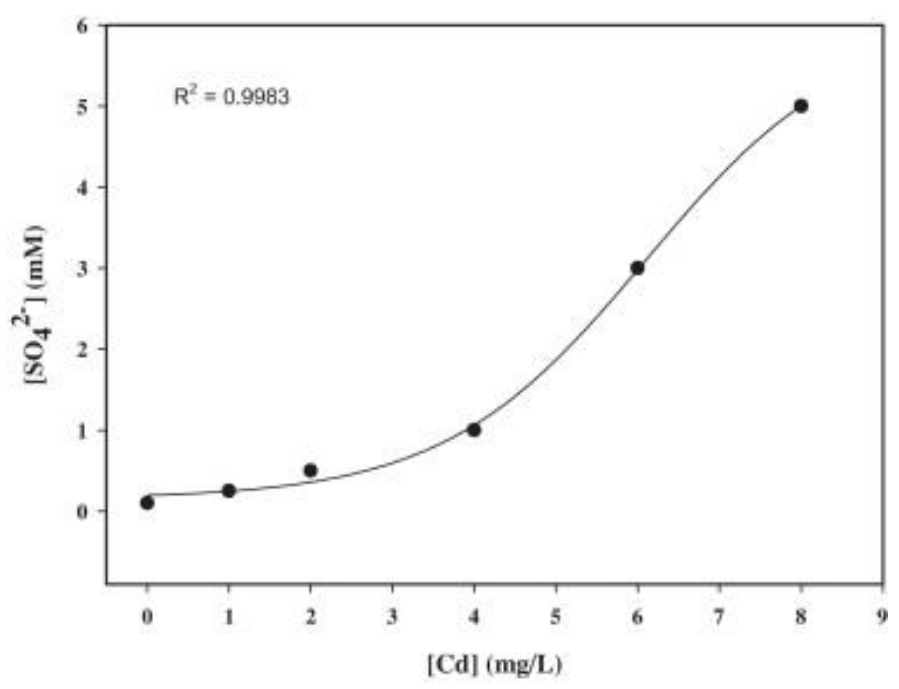

Fig. 2. Sulphate concentrations in the culture medium necessary to achieve the maximum final cell density obtained for each cadmium concentration. 
The growth rate is another important parameter to use when studying the effect of both factors on this microalga. The study of this parameter revealed that the growth rate was affected by both factors. The cadmium effect was inversely proportional to its concentration (Fig. 3). An increase in the concentration of this metal led to a decrease in the growth rate. The highest cadmium concentration $(8 \mathrm{mg} / \mathrm{L})$ caused the total inhibition of the growth rate. On the contrary, sulphate had a direct effect on this parameter: as the sulphate concentration increased also the growth rate increased until reaching a maximum value, different for each cadmium concentration. The maximum growth rate was obtained in cultures with $0.1 \mathrm{mM}$ sulphate. However, from these maximum values a decrease in the growth rate was observed with the increase of sulphate concentration. These results clearly show the existence of substrate inhibition. The kinetic parameters obtained by fitting to the three growth models studied are summarized in Table 3. It can be seen that uncompetitive and non-competitive models were able to predict the experimental results fairly well, the competitive model being the one that obtained the lowest correlation coefficients. This Table also shows that an increase in the cadmium concentration reduced the specific cell growth constant $(\mu m)$ of this microalga. The sulphate saturation constant $(K s)$ was higher with the increase of cadmium concentration. Instead, the inhibition constant $(K I)$ was lower.

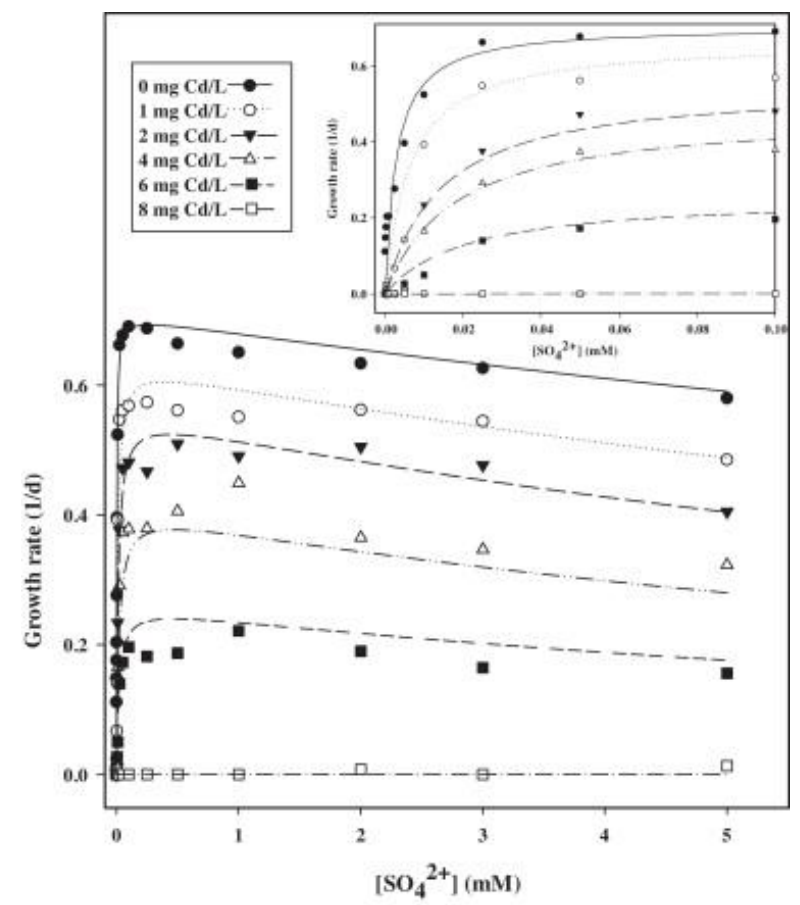

Fig. 3. Growth rates of $C$. moewusii cells after 4 days of exposure to different cadmium and sulphate concentrations (experimental data and model fitting). The upper figure is an enlargement of the interval $0-0.1 \mathrm{mM}$. 
Table 3. Kinetic parameters $( \pm$ SE, standard error) for the sulphate utilization in C. moewusii after 4 days of exposure to different cadmium concentrations.

\begin{tabular}{|c|c|c|c|c|c|c|c|c|c|c|c|c|}
\hline \multirow{2}{*}{$\begin{array}{l}{[\mathrm{Cd}]} \\
(\mathrm{mg} / \mathrm{L})\end{array}$} & \multirow[t]{2}{*}{$R^{2}$} & \multicolumn{3}{|l|}{ Competitive model } & \multicolumn{4}{|c|}{ Uncompetitive model } & \multicolumn{4}{|c|}{ Non-competitive model } \\
\hline & & $\mu m(1 / d)$ & $K s(\mathrm{mM})$ & $K I(\mathrm{mM})$ & $R^{2}$ & $\mu m(1 / d)$ & $K s(\mathrm{mM})$ & $K I(\mathrm{mM})$ & $R^{2}$ & $\mu m(1 / d)$ & $K s(\mathrm{mM})$ & $K I(\mathrm{mM})$ \\
\hline 0 & 0.900 & $13.147 \pm 1.710 \mathrm{E}+07$ & $0.043 \pm 5.786 \mathrm{E}+04$ & $0.002 \pm 0.001$ & 0.916 & $0.692 \pm 0.032$ & $0.003 \pm 0.001$ & $25.423 \pm 17.356$ & 0.916 & $0.692 \pm 0.032$ & $0.003 \pm 0.001$ & $25.401 \pm 17.333$ \\
\hline 1 & 0.948 & $7.135 \pm 3.643 \mathrm{E}+07$ & $0.093 \pm 1.449 \mathrm{E}+05$ & $0.008 \pm 0.002$ & 0.966 & $0.628 \pm 0.030$ & $0.009 \pm 0.002$ & $16.376 \pm 7.282$ & 0.966 & $0.629 \pm 0.030$ & $0.009 \pm 0.002$ & $16.367 \pm 7.284$ \\
\hline 2 & 0.920 & $5.512 \pm 1.552 \mathrm{E}+07$ & $0.132 \pm 3.73 \mathrm{E}+05$ & $0.012 \pm 0.004$ & 0.940 & $0.562 \pm 0.041$ & $0.015 \pm 0.005$ & $13.933 \pm 8.083$ & 0.940 & $0.562 \pm 0.042$ & $0.015 \pm 0.005$ & $13.919 \pm 8.087$ \\
\hline 4 & 0.936 & $4.567 \pm 1.13 \mathrm{E}+07$ & $0.169 \pm 4.191 \mathrm{E}+05$ & $0.015 \pm 0.004$ & 0.965 & $0.462 \pm 0.027$ & $0.020 \pm 0.005$ & $10.771 \pm 4.098$ & 0.965 & $0.462 \pm 0.027$ & $0.020 \pm 0.005$ & $10.750 \pm 4.100$ \\
\hline 6 & 0.938 & $3.083 \pm 6.306 \mathrm{E}+06$ & $0.253 \pm 5.197 \mathrm{E}+05$ & $0.016 \pm 0.005$ & 0.969 & $0.226 \pm 0.013$ & $0.022 \pm 0.005$ & $10.348 \pm 3.641$ & 0.969 & $0.226 \pm 0.013$ & $0.022 \pm 0.005$ & $11.327 \pm 3.677$ \\
\hline 8 & * & $*$ & $*$ & * & * & * & * & $*$ & * & $*$ & $*$ & $*$ \\
\hline
\end{tabular}

* No significant regression. 
The uncompetitive model was chosen to establish a mathematical model that links both factors. In this model, the sulphate concentration that yields the maximum growth rate $\left(\mu_{\max }\right)$ is given by the following equation:

$$
\left[\mathrm{SO}_{4}{ }^{2-}\right]=\left(\mathrm{K}_{\mathrm{S}} \mathrm{K}_{\mathrm{I}}\right)^{1 / 2}
$$

Thus, Table 4 shows the sulphate concentration necessary to achieve the maximum growth rate (calculated by Eq. (5)) depending on the cadmium concentration. It can be observed that with the increase in the metal concentration a higher sulphate concentration was required.

Table 4. Sulphate concentrations necessary to achieve the maximum growth rate in relation to the cadmium concentration, obtained by means of equation 5 .

\begin{tabular}{ll}
\hline$[\mathrm{Cd}](\mathrm{mg} / \mathrm{L})$ & {$\left[\mathrm{SO}_{4}{ }^{2-}\right](\mathrm{mM})$} \\
\hline 0 & 0.276 \\
1 & 0.384 \\
2 & 0.457 \\
\hline
\end{tabular}

Fig. 4 shows the relationship of each of the kinetic parameters (obtained with the uncompetitive model) $v s$. the cadmium concentration. Substituting the equations obtained from the regression analyses of these data in Eq. (3), a model for the specific growth rate of $C$. moewusii in terms of sulphate and cadmium concentrations was obtained (Eq. (6)).

$$
\mu=\frac{(0.7075-0.0744[\mathrm{Cd}])\left[\mathrm{SO}_{4}{ }^{2-}\right]}{0.0028+0.0072[\mathrm{Cd}]-0.0007[\mathrm{Cd}]^{2}+\left[\mathrm{SO}_{4}{ }^{2-}\right]+\left[\mathrm{SO}_{4}{ }^{2-}\right]^{2} / 10.3557+14.9533 \times e^{(-0.8226 \times][\mathrm{Cd}]]}}
$$

(6)

Lines in Fig. 3 were drawn using Eq. (6). It can be seen that the experimental data fit well to the growth model derived. The correlation coefficients were higher than 0.97 . Similarly, an equation for non-competitive model (equation not shown) was obtained, but in this case, the correlation coefficients were less than 0.92 . For this reason, this model was not considered. 

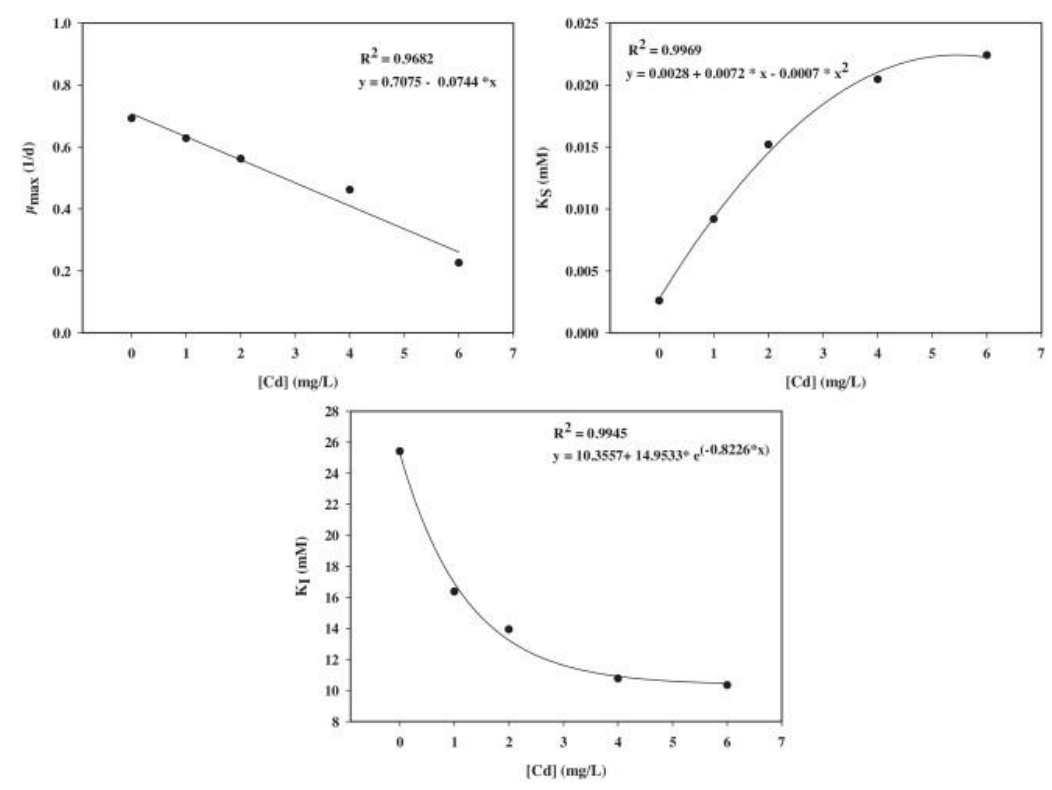

The $\mathrm{EC}_{50 / 4 \mathrm{~d}}$ values for cadmium estimated from concentration-response curves and depending on the different sulphate concentrations are shown in Fig. 5. From this figure it can be seen that with the increase of sulphate concentration also the cadmium tolerance of this microalga increased. Thus, considering the values obtained for $\mathrm{EC}_{50}$ (based on nominal cadmium concentration), the cadmium tolerance was proportional to the sulphate concentration up to a maximum threshold. The $\mathrm{EC}_{50}$ estimated for low sulphate concentration was only $0.5 \mathrm{mg} \mathrm{Cd} / \mathrm{L}$; however, the maximum value reached was $4.46 \pm 0.42 \mathrm{mg} \mathrm{Cd} / \mathrm{L}$ with $1 \mathrm{mM}$ sulphate in the culture medium. A higher sulphate concentration than $1 \mathrm{mM}$ did not produce a significant increase in the tolerance, even a decrease in this ability was observed.

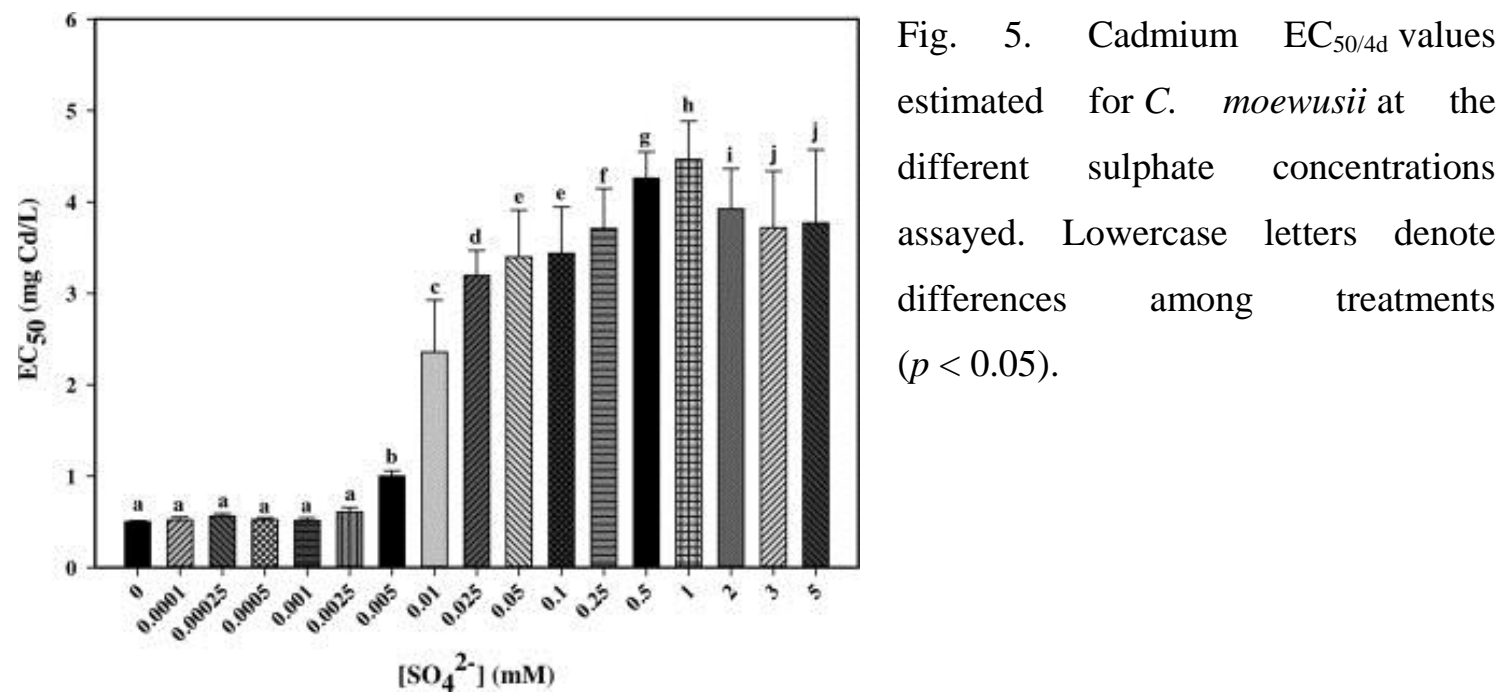




\subsection{Effects of sulphate and cadmium on the low-molecular mass thiol}

compounds

The synthesis of low-molecular mass thiol compounds in C. moewusii exposed to different cadmium and sulphate concentrations are shown in Fig. 6 and Fig. 7. The detected levels of the amino acid cysteine were significantly higher than those of other thiol compounds (GSH and $\gamma$-Glu-Cys) (Fig. 6). The cysteine concentration increased with the cadmium concentration. The maximum values were obtained in the concentration of $6 \mathrm{mg} / \mathrm{L}$, decreasing in the following cadmium concentration. In addition, this amino acid had a progressive increase with the increase of sulphate concentration, reaching maximum values in medium-high concentrations of this nutrient ( $\geq 0.01 \mathrm{mM}$ ) (Fig. 6a). The levels of $\gamma$-Glu-Cys were always lower than those of the rest of thiols and did not vary significantly in relation to cadmium but varied with the sulphate concentrations. This thiol had a significant increase with the increase of the sulphate concentrations. In cadmium-free cultures, this compound reached a maximum level when the sulphate concentration added to the culture medium was $0.1 \mathrm{mM}$. The amount of $\gamma$-Glu-Cys remained constant from this concentration. Nevertheless, GSH synthesis was influenced by the action of both factors. The GSH levels decreased slightly with the increase of cadmium concentration for a given amount of sulphate. By contrast, the amount of GSH had a significant increase with the increase of the sulphate concentrations. In cadmium-free cultures, this compound reached a maximum level when the sulphate concentration in the culture medium was $0.1 \mathrm{mM}$. The amount of GSH remained constant from this concentration.

PCs were the most abundant thiols in the cultures with cadmium. PCs of two $\left(\mathrm{PC}_{2}\right)$, three $\left(\mathrm{PC}_{3}\right)$, four $\left(\mathrm{PC}_{4}\right)$ and five $\left(\mathrm{PC}_{5}\right)$ subunits, and their respective desglycine phytochelatins (dPCs) were identified in cultures of this microalga treated with this metal (Fig. 7). PCs were not detected in control cultures without metal. $C$. moewusii cultures treated with cadmium showed an increase in the PC levels due to the increase in the metal concentration, except in the highest concentration $(8 \mathrm{mg} / \mathrm{L})$. Furthermore, there was a significant increase in PCs of medium chain, the content in $\mathrm{PC}_{3}$ and $\mathrm{PC}_{4}$ was significantly predominant with respect to other $\mathrm{PC}$ chains. $\mathrm{PC}_{5}$ was only detected from cultures treated with $2 \mathrm{mg} \mathrm{Cd} / \mathrm{L}$ and it was the longest chain detected. Although cadmium clearly induced the PC synthesis, the amount synthesized was significantly dependent on the sulphate concentration. With the increase in the 
concentration of this compound, the amount of PCs was higher for a same concentration of metal (Fig. 7). The highest PC content was in the combination of $4 \mathrm{mg} \mathrm{Cd} / \mathrm{L}$ and $1 \mathrm{mM}$ sulphate, which also corresponded with the highest $\mathrm{EC}_{50}$ value (Fig. 5).

In addition, Fig. 6 and Fig. 7 show that the total thiol content increased with the increase of cadmium and sulphate concentration. However, when the metal concentration was very high, this tendency was reversed, reducing the total content of thiols synthesized by the microalga. The highest content occurred in cultures exposed to 4 and $6 \mathrm{mg} \mathrm{Cd} / \mathrm{L}$ and containing the highest sulphate concentrations tested.
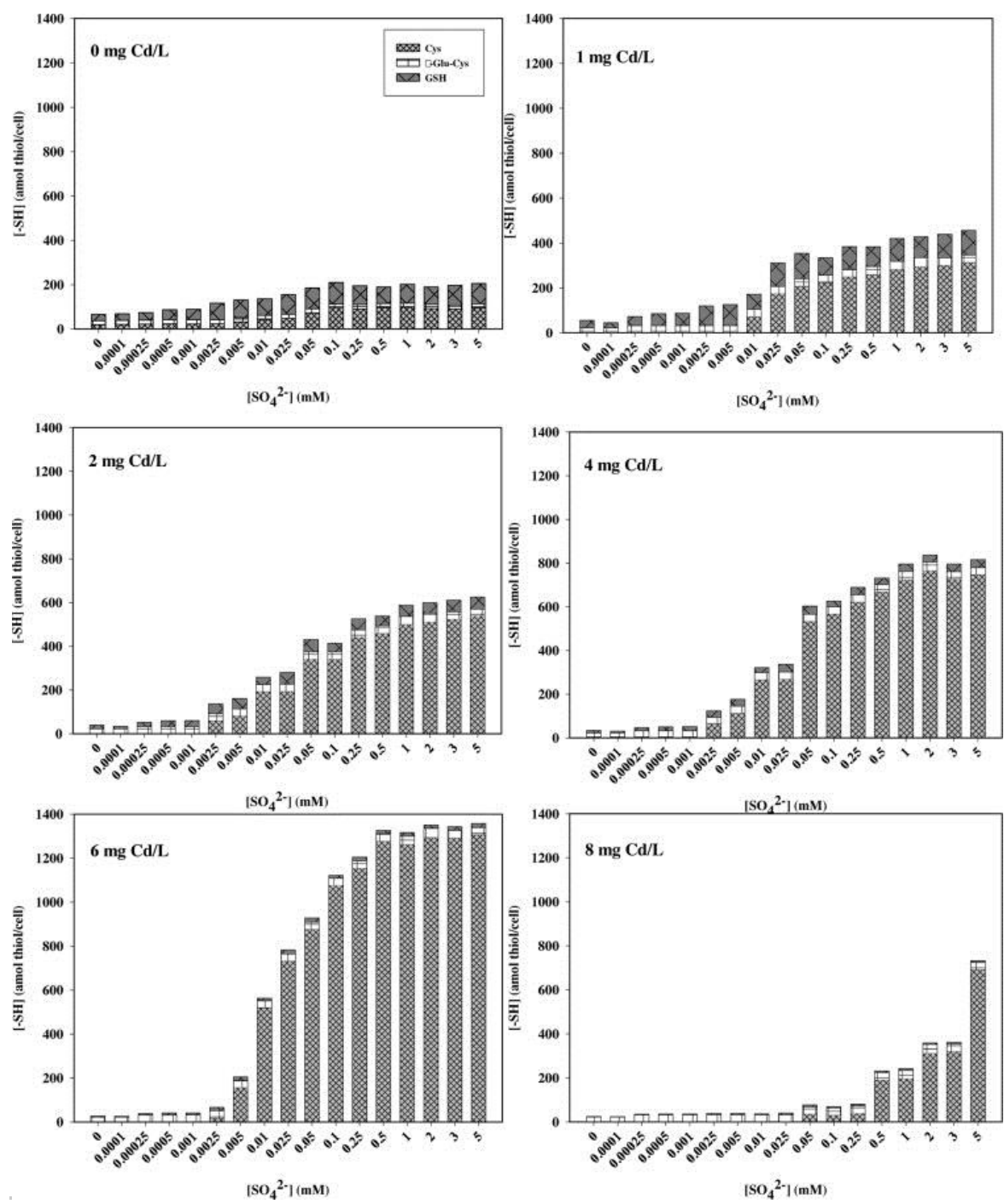

Fig. 6. Production of cysteine, $\gamma-\mathrm{Glu}-\mathrm{Cys}$ and GSH in C. moewusii cells in response to different cadmium concentrations with different sulphate concentrations after 4 days of exposure. 


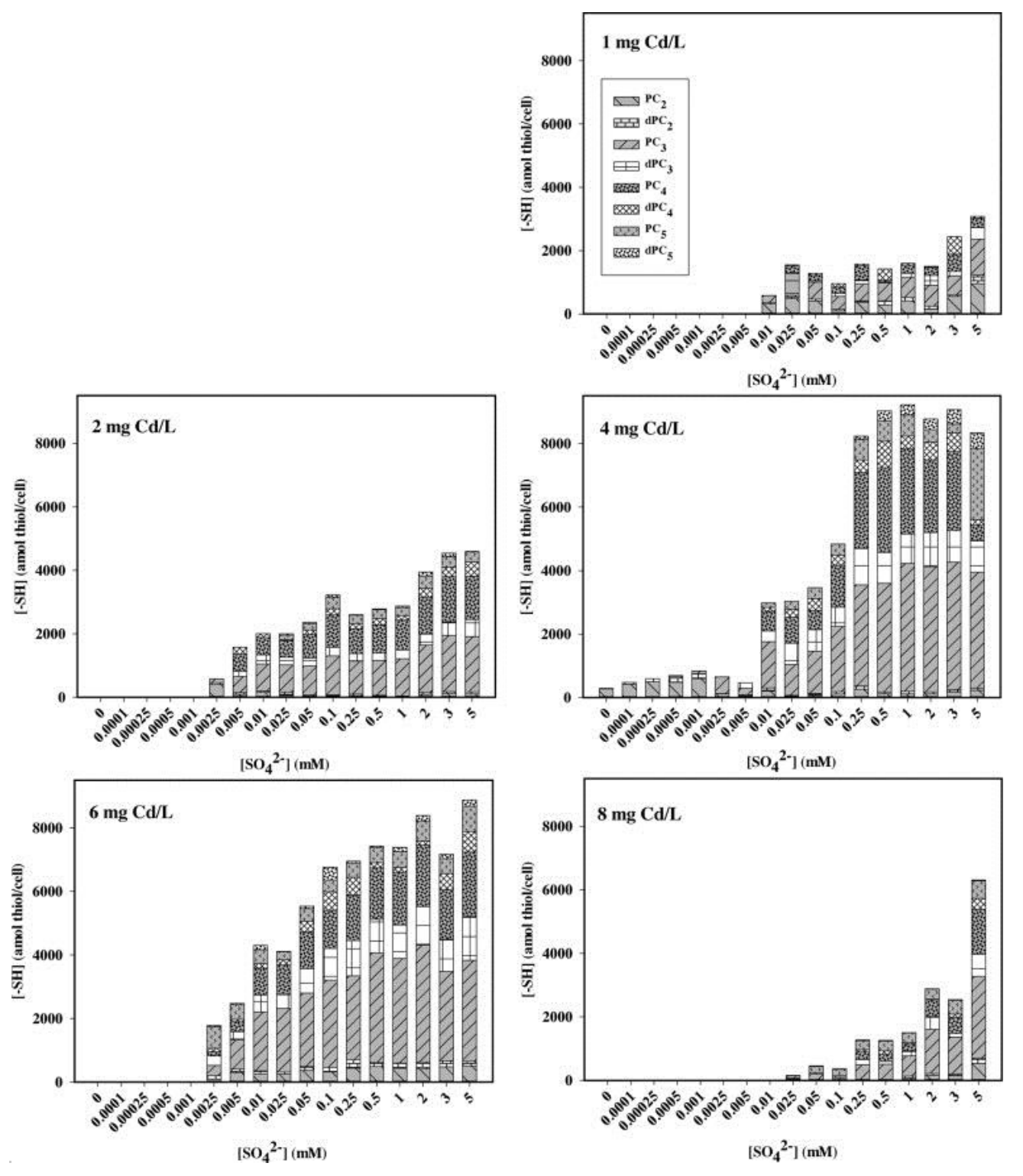

Fig. 7. Production of PCs in C. moewusii cells in response to different cadmium concentrations with different sulphate concentrations after 4 days of exposure.

\section{DISCUSSION}

Sulphur is an essential macroelement that plays a major role in processes of growth and development of living organisms. In the case of autotrophic organisms, sulphur is incorporated mainly from sulphate and therefore this compound is an important nutrient. However, when cadmium is present in the environment, sulphate is much more than a simple nutrient, playing an indirect protective function against this toxic element. In fact, environmental conditions are believed to be important for 
tolerance to metals. Although there are many described environmental factors influencing the toxicity of metals, perhaps sulphate should have more attention. In the present work, the protective effect of sulphate was studied by exposing the freshwater microalga $C$. moewusii to different cadmium concentrations in the presence of different sulphate concentrations in the nutrient solution. This bifactorial design allowed highlighting the interaction between these two factors. C. moewusii is a good model for these studies because it has been commonly used as test microorganism in various genetical ( Lee et al., 1991), physiological (Bernstein, 1966) and toxicological bioassays (studies with herbicides) (Prado et al., 2011); but there are few data available regarding to metals (Suárez et al., 2010) in this species. With the experimental design used in the present work, it was also possible to study the kinetic parameters for sulphate utilization by this microalga and the effect of cadmium on them. There are several studies in roots of higher plants ( Alves de Oliveira et al., 2009, Mendoza-Cózatl et al., 2005 and Nocito et al., 2006) and in Euglena gracilis ( García-García et al., 2012) on the sulphate uptake and the effect of cadmium on this process, but there is little information about its behaviour as nutrient in microalgal cells and the effect of cadmium on this behaviour.

In the present work, $C$. moewusii cultures were kept without sulphur in the nutrient solution for 21 days prior to experiments to effectively remobilize their Sreserves and to better observe the effect of sulphate. During this time, these cultures remained viable (data not shown). When the results of the present work were analyzed in the cadmium-free cultures, it was possible to observe that sulphate is obviously a nutrient (Fig. 1 and Fig. 3) with an optimum concentration of $0.1 \mathrm{mM}$ for the experimental conditions used in the present work. However, from this concentration the opposite effect was observed, this nutrient would be in excess generating a negative effect at higher concentrations. This response was also found with Fontinalis antipyretica when it was exposed to high sulphate concentrations (up to $1500 \mathrm{mg} / \mathrm{L}$ ) with the result of significant reductions in several biological parameters (Davies, 2007). The negative effects of this compound seem to be due to the creation of an unsustainable osmotic imbalance between the aquatic organisms and their surrounding environment. In fact, it is known that this effect depends on the water hardness (Elphick et al., 2011). C. moewusiiappears to be quite sensitive to these changes because such effects were already observed when the sulphate concentration in the medium was higher than $0.1 \mathrm{mM}$ (Fig. 1). Although Monod-type models are often incorporated into 
growth simulations where complexity must be kept to a minimum, the data obtained in the present work show that kinetics of sulphate utilization as substrate by these microalgal cells is governed by an uncompetitive inhibition model (Fig. 3 and Fig. 4), in which the number of active uptake sites limits the maximum uptake rate. The use of this type of model allowed greater biological accuracy in the present study.

When cadmium was added to the culture medium, there was a reduction of the $C$. moewusii growth, both in terms of final cell density and growth rate ( Fig. 1 and Fig. 3). However, this effect was smaller than expected as sulphate concentration was increased. All cadmium concentrations caused a dramatic growth inhibition of this microalga when the sulphate content in the medium was low (Fig. 1). The increase of sulphate allowed to alleviate this effect, which can be easily observed when the cadmium $\mathrm{EC}_{50}$ was calculated for the different sulphate concentrations (Fig. 5). Thus, when the sulphate concentration was the commonly used in the culture media (approx. $0.5 \mathrm{mM}$ ), the $\mathrm{EC}_{50}$ was $4.26 \pm 0.29 \mathrm{mg} \mathrm{Cd} / \mathrm{L}$. A similar result was obtained by Suárez et al. (2010)using this microalga exposed to the same metal. They obtained a value of $4.1 \pm 0.8 \mathrm{mg} \mathrm{Cd} / \mathrm{L}$ after 4 days of exposure and using Bristol as culture medium in their experimental conditions. This culture medium contains a total sulphate concentration of $0.5 \mathrm{mM}$. When the sulphate concentration was raised to $1 \mathrm{mM}$, the $\mathrm{EC}_{50}$ value increased still further, reaching $4.46 \pm 0.42 \mathrm{mg} \mathrm{Cd} / \mathrm{L}$. Precisely in these concentrations the highest content of thiol compounds was also obtained. Cadmium causes alterations in the regulation at the enzymatic and genetic level of the cysteine and glutathione biosynthesis (Mendoza-Cózatl et al., 2005). In aquatic plant species during cadmium stress, the ATP sulfurylase activity increased between 1.5 and 3.5 times (Alves de Oliveira et al., 2009); in E. graciliscells exposed to this metal, the activity of the sulphate transporters was significantly increased (García-García et al., 2012). These alterations appear to lead to an increase in the biosynthesis of these compounds and finally of PCs. PCs have a clear role in cadmium tolerance, supported by a range of biochemical and genetic evidences. Over time, several studies have demonstrated that cadmium is the strongest inductor of PC biosynthesis in several species (Ahner and Morel, 1995). The PC synthesis is a common detoxification response to cadmium in microalgal cells (Lavoie et al., 2009). As expected, in the present study, $C$. moewusii showed an increase in the PC levels when the cadmium concentration increased (Fig. 7), the highest amount of PCs being achieved in the cadmium 
concentration of $4 \mathrm{mg} / \mathrm{L}$ (around the highest $\mathrm{EC}_{50}$ value). However, the ability to synthesize PCs was also strongly affected by the sulphate concentration. The amount of PCs increased with the sulphate concentration at the same time that also increased metal tolerance. The PC biosynthesis is clearly dependent on sulphur metabolism. Due to this relationship, the type and amount of low-molecular mass thiol compounds synthesized in response to cadmium also depended on the sulphate concentrations. All soluble thiols synthesized by $C$. moewusii changed with cadmium and sulphate treatments. The exposure to cadmium would induce an additional sink of sulphate due to the need to synthesize more thiol compounds (driven by the PC biosynthesis). This need can be satisfied when the amount of sulphate in the medium is sufficient. Therefore, no step or enzyme involved in this biosynthesis appears to be affected by the toxic effect of cadmium. In fact, the data obtained in the present work showed that the increase in the amount of sulphate in the medium allowed a higher tolerance to this metal since it promoted a higher thiol compound biosynthesis. Nocito et al. (2002) also found that the rate of sulphate uptake by maize roots grown in the presence of cadmium was twice that of the control. Some studies on the addition of sulphur to Cd-treated higher plants, as Brassica campestris, have revealed an enhanced capacity for GSH synthesis due to S-fertilization. This application of sulphur helped in reducing cadmium toxicity (Anjum et al., 2008). This reduction was also observed in the present study with $C$. moewusii, but here the PC content, more than the GSH content, was responsible of this tolerance. Thus, in microalgae exposed to cadmium, the increase of sulphate concentration allows an increase of PC biosynthesis, increasing the tolerance to higher doses of this metal ( Fig. 5 and Fig. 6).

However, PCs are not the unique intracellular defence against the cytotoxic action of this metal in $C$. moewusii. Thus, in cultures treated with cadmium was observed an increase in the intracellular levels of cysteine. This same fact was also reported by Suárez et al. (2010) in this microalga. Cysteine could act as a defence mechanism not only for participating in PC biosynthesis but also directly as metal chelator. In fact, the cysteine content was higher than that of GSH when cadmium was present in the medium. The amount of GSH decreased only slightly with the increase in the PC levels (Fig. 6). This would suggest that the intracellular GSH was consumed during the PC biosynthesis and replaced quickly by new synthesis from the sulphur of the medium. 
Another important effect of cadmium focuses on the effect that this metal had on the kinetics of sulphate utilization. Cadmium caused changes in the kinetics parameters. The half-saturation constant $(K S)$ is an index of affinity to this nutrient, this constant increased with the cadmium concentration, indicating a higher need of sulphate to achieve half of the corresponding maximum growth rate when the cadmium concentration increases in the culture medium. Instead, $K I$ decreased, the amount of sulphate that reduces the maximum growth rate is lower as cadmium increases, that is, a synergistic effect can be observed when the sulphate concentration exceeds the optimum. Eq. (6) was built taking into account the effect of these two factors on the kinetic parameters and using an uncompetitive inhibition model. In this way, it was possible to model the cadmium effect on the growth of this microalga as a function of the sulphate concentration in the medium.

The toxicity of this metal has been verified in many studies involving both freshwater and marine microalgae. Although toxicity to cadmium depends on culture conditions, some relevant data obtained for other microalgae can serve as reference (Table 5). These values seem to suggest that, in general, freshwater microalgae are more sensitive to this metal than their homologous marine counterparts. One possible explanation, taking into account the results of the present study, is that in marine environments there is a higher abundance of sulphate, allowing an increased synthesis of PCs and related compounds. For example, the marine microalga Tetraselmis suecica exposed to cadmium showed higher values in the amount of thiol compounds synthesized ( Pérez-Rama et al., 2006) compared with $C$. moewusii.

Finally, the results obtained in this study have an interesting environmental impact. Taking into account this protective effect of sulphate on cadmium toxicity, those environments in which sulphate availability is low, a higher toxicity of this metal on microalgal populations is expected. In contrast, sulphate-rich environments could better tolerate its effects. One possible way to act in environments contaminated with cadmium would be to increase the bioavailability of sulphate, especially when its bioavailability is low. However, it is necessary take into account that high concentrations can have the opposite effect (substrate inhibition). In addition, a desirable feature that the designated organisms for bioremediation should have is an efficient mechanism for metal sequestration or inactivation. Thus, a suitable increase in 
PC biosynthesis would improve the results of cadmium removal. A higher sulphate bioavailability could respond to this demand, generating a more successful strategy.

Table 5. $\mathrm{EC}_{50}$ values for cadmium obtained with different species of freshwater and marine microalgae.

\begin{tabular}{lll}
\hline Microalgae species & $\mathrm{EC}_{50 / \mathrm{day}}(\mathrm{mg} \mathrm{Cd} / \mathrm{L})$ & Reference \\
\hline Freshwater microalgae & & \\
$\begin{array}{l}\text { Pseudokirchneriella subcapitata } \\
\text { Chlamydomonas sp. }\end{array}$ & $\mathrm{EC}_{50 / 4 \mathrm{~d}}=0.009$ & (Källqvist, 2009) \\
Chlorella sp. & $\mathrm{EC}_{50 / 12 \mathrm{~d}}=22.48$ & (Aguilera and Amils, 2005) \\
Chlorella vulgaris & $\mathrm{EC}_{50 / 7 \mathrm{~d}}=0.34$ & (Kaplan et al., 1995) \\
$\begin{array}{l}\text { Desmodesmus subspicatus } \\
\text { Selenastrum capricornutum }\end{array}$ & $\mathrm{EC}_{50 / 4 \mathrm{~d}}=0.10$ & (Rachlin and Grosso, 1993) \\
Ankistrodesmus falcatus & $\mathrm{EC}_{50 / 3 \mathrm{~d}}=0.30$ & (Baścik-Remisiewicz et al., \\
Chlorella pyrenoidosa & $\mathrm{EC}_{50 / 4 \mathrm{~d}}=0.29$ & (Turbak et al., 1986) \\
Marine microalgae & $\mathrm{EC}_{50 / 4 \mathrm{~d}}=6.69$ & (Mednarz and Warkowska- \\
Isochrysis galbana & & Dratnal, 1985) \\
Tetraselmis gracilis & $\mathrm{EC}_{50 / 5 \mathrm{~d}}=0.74$ & (Yap et al., 2004) \\
Tetraselmis suecica & $\mathrm{EC}_{50 / 4 \mathrm{~d}}=1.8$ & (Okamoto et al., 1996) \\
Dunaliella salina & $\mathrm{EC}_{50 / 6 \mathrm{~d}}=7.9$ & (Pérez-Rama et al., 2002) \\
& $\mathrm{EC}_{50 / 4 \mathrm{~d}}=48.9$ & (Folgar et al., 2009) \\
\hline
\end{tabular}

\section{CONCLUSIONS}

Sulphate is an important nutrient not only for its essentiality but also for its indirect protective effect against cadmium toxicity. The results with the microalga $C$. moewusiishowed that the increase of sulphate in the nutrient solution allowed a higher tolerance to cadmium. The $\mathrm{EC}_{50 / 4 \mathrm{~d}}$ increased with the increase of sulphate concentration, the highest value being $4.46 \pm 0.42 \mathrm{mg} \mathrm{Cd} / \mathrm{L}$ when the sulphate concentration added to culture medium was $1 \mathrm{mM}$. The increase in the amount of sulphate allowed for an increase in the biosynthesis of low-molecular mass thiol compounds, such as phytochelatins (important compounds for cadmium tolerance). This response is only effective if the sulphate concentration is enough to allow for the synthesis of these compounds to fulfil the high demand for them generated by the presence of cadmium. 
From an environmental perspective, it seems clear that an increase in the sulphate concentration, in deficient environments, could alleviate the toxic effect of this metal; however, a relative excess of sulphate is also negative. The results obtained show a substrate inhibition for this nutrient.

\section{REFERENCES}

Aguilera, A., Amils, R., 2005. Tolerance to cadmium in Chlamydomonas sp. (Chlorophyta) strains isolated from an extreme acidic environment, the Tinto River (SW, Spain). Aquat. Toxicol. 75, 316-329.

Ahner, B.A., Morel, F.M.M., 1995. Phytochelatin production in marine algae. 2. Induction by various metals. Limnol. Oceanogr. 40, 658-665.

Alves de Oliveira, J., Cambraia, J., Valle de Sousa, M., Oliva, M.A., 2009. Sulphate uptake and metabolism in water hyacinth and salvinia during cadmium stress. Aquat. Bot. 91, 257261.

Anjum, N.A., Umar, S., Ahmad, A., Iqbal, M., Khan, N.A., 2008. Sulphur protects mustard (Brassica campestris L.) from cadmium toxicity by improving leaf ascorbate and glutathione. Plant Growth Regul. 54, 271-279.

Bascik-Remisiewicz, ' A.,Aksmann,A., Zak, ' A.,Kowalska,M., Tukaj, Z., 2011. Toxicity of cadmium, anthracene, and their mixture to Desmodesmus subspicatus estimated by algal growth-inhibition ISO standard test. Arch. Environ. Contam. Toxicol. 60, 610-617.

Bednarz, T., Warkowska-Dratnal, H., 1985. Toxicity of zinc, cadmium, lead, copper, and their mixture for Chlorella pyrenoidosa. Acta Hydrobiol. 25-26, 389-400.

Bernstein, E.O., 1966. Physiology of an obligate photoautotroph (Chlamydomonas moewusii). II. The effect of light-dark cycles on cell division. Exp. Cell Res. 41, 307-315.

Bräutigam, A., Schaumloffel, D., Preud'homme, H., Thondorf, I., Wesenberg, D., 2011. Physiological characterization of cadmium-exposed Chlamydomonas reinhardtii. Plant Cell Environ. 34, 2071-2082.

Brown, T.E., Richardson, F.L., Vaughn, M.L., 1967. Development of red pigmentation in Chlorococcum wimmeri (Chlorophyta: Chlorococcales). Phycologia 6, 167-184.

Brzóska, M.M., Moniuszko-Jakoniuk, J., 2001. Interactions between cadmium and zinc in the organism. Food Chem. Toxicol. 39, 967-980.

Cobbett, C.S., Goldsbrough, P., 2002. Phytochelatins and metallothioneins: roles in heavy metal detoxification and homeostasis. Annu. Rev. Plant Biol. 53, 159-182.

Chen, J., Zhou, J., Goldsbrough, P.B., 1997. Characterization of phytochelatin synthase from tomato. Physiol. Plant. 101, 162-172.

Dameron, C.T., Winge, D.R., 1990. Characterization of peptide-coated cadmiumsulfide crystallites. Inorg. Chem. 29, 1343-1348.

Davies, T.D., 2007. Sulphate toxicity to the aquatic moss, Fontinalis antipyretica. Chemosphere $66,444-451$. 
Elphick, J.R., Davies, M., Gilron, G., Canaria, E.C., Lo, B., Bailey, H.C., 2011. An aquatic toxicological evaluation of sulfate: the case for considering hardness as a modifying factor in setting water quality guidelines. Environ. Toxicol. Chem. 30, 247-253.

Folgar, S., Torres, E., Pérez-Rama, M., Cid, A., Herrero, C., Abalde, J., 2009. Dunaliella salina as a marine microalga highly tolerant to but a poor remover of cadmium. J. Hazard. Mater. 165, 486-493.

García-García, J.D., Olin-Sandoval, V., Saavedra, E., Girard, L., Hernández, G., MorenoSánchez, R., 2012. Sulfate uptake in photosynthetic Euglena gracilis. Mechanisms of regulation and contribution to cysteine homeostasis. BBA-Gen. Subj. $1820,1567-1575$.

Grill, E., Winnacker, E.L., Zenk, M.H., 1987. Phytochelatins, a class of heavy-metalbinding peptides from plants, are functionally analogous to metallothioneins. PNAS 84, 439-443.

Hell, R., Dahl, C., Knaff, D.B., Leustek, T., 2008. Sulfur Metabolism in Phototrophic Organisms. Springer Netherlands, The Netherlands.

Heuillet, E., Moreau, A., Halpren, S., Jeanne, N., Puiseux-Dao, S., 1986. Cadmium binding to a thiol molecule in vacuoles of Dunaliella bioculata contaminated with $\mathrm{CdCl} 2$ : electron probe microanalysis. Biol. Cell 58, 79-86.

Holmer, M., Storkholm, P., 2001. Sulphate reduction and sulphur cycling in lake sediments: a review. Freshwater Biol. 46, 431-451.

Jacobson, K.B., Turner, J.E., 1980. The interaction of cadmium and certain other metal ions with proteins and nucleic acids. Toxicology 16, 1-37.

Järup, L., 2003. Hazards of heavy metal contamination. Br. Med. Bull. 68, 167-182.

Källqvist, T., 2009. Effect of water hardness on the toxicity of cadmium to the green alga Pseudokirchneriella subcapitata in an artificial growth medium and nutrientspiked natural lake waters. J. Toxicol. Environ. Health Part A 72, 277-283.

Kaplan, D., Heimer, Y.M., Abeliovich, A., Goldsbrough, P.B., 1995. Cadmium toxicity and resistance in Chlorella sp. Plant Sci. 109, 129-137.

Lavoie, M., Le Faucheur, S., Fortin, C., Campbell, P.G., 2009. Cadmium detoxification strategies in two phytoplankton species: metal binding by newly synthesized thiolated peptides and metal sequestration in granules. Aquat. Toxicol. 92, 65-75.

Lee, R.W., Dumas, C., Lemieux, C., Turmel, M., 1991. Cloning and characterization of the Chlamydomonas moewusii mitochondrial genome. Mol. Gen. Genet. 231, 53-58.

Magdaleno, A., Gomez, C.E., Velez, C.G., Accorinti, J., 1997. Preliminary toxicity tests using the green alga, Ankistrodesmus falcatus. Environ. Toxic. Water 12, 11-14.

Mason, A.Z., Jenkins, K.D., 1995. Metal detoxification in aquatic organisms. In: Tessier, A., Turner, D.R. (Eds.), Metal Speciation and Bioavailability in Aquatic Systems. John Wiley \& Sons Ltd, California, pp. 479-608.

Mehra, R.K., Mulchandani, P., Hunter, T.C., 1994. Role of CdS quantum crystallites in cadmium resistance in Candida Glabrata. Biochem. Biophys. Res. Commun 200, 11931200 . 
Mendoza-Cózatl, D., Loza-Tavera, H., Hernández-Navarro, A., Moreno-Sánchez, R., 2005. Sulfur assimilation and glutathione metabolism under cadmium stress in yeast, protists and plants. FEMS Microbiol. Rev. 29, 653-671.

Mislin, H., Ravera, O., 1986. Cadmium in the environment. Birkhäuser Verlag Basel, Basel, Switzerland. Nocito, F.F., Lancilli, C., Crema, B., Fourcoy, P., Davidian, J.C., Sacchi, G.A., 2006. Heavy metal stress and sulfate uptake in maize roots. Plant Physiol. 141, $1138-1148$.

Nocito, F.F., Pirovano, L., Cocucci, M., Sacchi, G.A., 2002. Cadmium-induced sulfate uptake in maize roots. Plant Physiol. 129, 1872-1879.

Noël, L., Huynh-Delerme, C., Guérin, T., Huet, H., Frémy, J.-M., Kolf-Clauw, M., 2006. Cadmium accumulation and interactions with zinc, copper, and manganese, analysed by ICP-MS in a long-term Caco-2 TC7 cell model. Biometals 19, 473-481.

Okamoto, O.K., Asano, C.S., Aidar, E., Colepicolo, P., 1996. Effects of cadmium on growth and superoxide dismutase activity of the marine microalga Tetraselmis gracilis (Prasinophyceae). J. Phycol. 32, 74-79.

Ortiz, D.F., Ruscitti, T., McCue, K.F., Ow, D.W., 1995. Transport of metal-binding peptides by HMT1, a fission yeast ABC-type vacuolar membrane protein. J. Biol. Chem. 270, 47214728.

Pawlik-Skowronska, ' B., 2001. Phytochelatin production in freshwater algae Stigeoclonium in response to heavy metals contained in mining water; effects of some environmental factors. Aquat. Toxicol. 52, 241-249.

Pérez-Rama, M., Abalde, J., Herrero, C., Torres, E., 2002. Cadmium removal by living cells of the marine microalga Tetraselmis suecica. Bioresour. Technol. 84, 265-270.

Pérez-Rama, M., Torres, E., Abalde, J., 2005. Capillary zone electrophoresis for analysis of phytochelatins and other thiol peptides in complex biological samples derivatized with monobromobimane. Electrophoresis 26, 610-620.

Pérez-Rama, M., Torres, E., Abalde, J., 2006. Composition and production of thiol constituents induced by cadmium in the marine microalga Tetraselmis suecica. Environ. Toxicol. Chem. 25, 128-136.

Prado, R., Rioboo, C., Herrero, C., Cid, A., 2011. Characterization of cell response in Chlamydomonas moewusii cultures exposed to the herbicide paraquat:induction of chlorosis. Aquat. Toxicol. 102, 10-17.

Prévot, P., Soyer-Gobillard, M.O., 1986. Combined action of cadmium and selenium on two marine dinoflagellates in culture, Prorocentrum micans Ehrgb. and Crypthecodinium cohnii Biecheler. J. Protozool. 33, 42-47.

Rachlin, J.W., Grosso, A., 1993. The growth response of the green alga Chlorella vulgaris to combined divalent cation exposure. Arch. Environ. Contam. Toxicol 24, 16-20.

Rauser, W.E., 1990. Phytochelatins. Annu. Rev. Biochem. 59, 61-86.

Steffens, J.C., 1990. The heavy metal-binding peptides of plants. Annu. Rev. Plant Physiol. Plant Mol. Biol. 41, 553-575.

Stohs, S.J., Bagchi, D., 1995. Oxidative mechanisms in the toxicity of metal ions. Free Radic. Biol. Med. 18, 321-336. 
Suárez, C., Torres, E., Pérez-Rama, M., Herrero, C., Abalde, J., 2010. Cadmium toxicity on the freshwater microalga Chlamydomonas moewusii Gerloff: biosythesis of thiol compounds. Environ. Toxicol. Chem 29, 1-7.

Sunda, G.W., Huntsman, S.A., 1996. Antagonisms between cadmium and zinc toxicity and manganese limitation in a coastal diatom. Limnol. Oceanogr. 41, 373-387.

Torres, E., Cid, A., Fidalgo, P., Herrero, C., Abalde, J., 1997. Long-chain class III metallothioneins as a mechanism of cadmium tolerance in the marine diatom Phaeodactylum tricornutum Bohlin. Aquat. Toxicol. 39, 231-246.

Turbak, S.C., Olson, S.B., Mcfeters, G.A., 1986. Comparison of algal assay systems for detecting waterborne herbicides and metals. Water Res. 20, 91-96.

Vatamaniuk, O.K., Mari, S., Lang, A., Chalasani, S., Demkiv, L.O., Rea, P.A., 2004. Phytochelatin synthase, a dipeptidyltransferase that undergoes multisite acylation with gamma-glutamylcysteine during catalysis: stoichiometric and site-directed mutagenic analysis of arabidopsis thaliana PCS1-catalyzed phytochelatin synthesis. J. Biol. Chem. $279,22449-22460$.

WHO, 1992. Cadmium, Environmental Health Criteria 134.International Programme on Chemical Safety, Geneva.

Wirtz, M., Droux, M., 2005. Synthesis of the sulfur amino acids: cysteine and methionine. Photosynth. Res. 86, 345-362.

Yap, C.K., Ismail, A., Omar, H., Tan, S.G., 2004. Toxicities and tolerances of $\mathrm{Cd}, \mathrm{Cu}, \mathrm{Pb}$ and $\mathrm{Zn}$ in a primary producer (Isochrysis galbana) and in a primary consumer (Perna viridis). Environ. Int. 29, 1097-1104.

Zenk, M.H., 1996. Heavy metal detoxification in higher plants-a review. Gene 179, 21-30. 